\title{
Duration of the Third Stage of Labor and Estimated Blood Loss in Twin Vaginal Deliveries
}

\author{
Julie R. Whittington, MD ${ }^{1}$ Megan Pagan, $\mathrm{MD}^{1} \quad$ Kristen Daugherty, $\mathrm{BS}^{1} \quad$ Kelly Cummings, MD 2 \\ Songthip T. Ounpraseuth, $\mathrm{PhD}^{3}$ Lauren Eads, MD ${ }^{1}$ Everett F. Magann, MD ${ }^{1}$
}

${ }^{1}$ Division of Maternal Fetal Medicine, Department of Obstetrics \&

Address for correspondence Julie R. Whittington, MD, Division of Gynecology, University of Arkansas for Medical Sciences, Little Rock, Arkansas

2 Department of Obstetrics and Gynecology, Marshall Health, Huntington, West Virginia Maternal Fetal Medicine, Department of Obstetrics \& Gynecology, University of Arkansas for Medical Sciences, 4301 W. Markham Street Slot \#518, Little Rock, AR 72205 (e-mail: jrwhittington@uams.edu).

${ }^{3}$ Department of Biostatistics, University of Arkansas for Medical

Sciences, Little Rock, Arkansas

Am J Perinatol Rep 2020;10:e330-e334.

\begin{abstract}
Objective The main aim of this study was to characterize the duration of the third stage of labor and estimated blood loss in twin vaginal deliveries.

Study Design This was a retrospective case-control study. The data was collected from deliveries at the University of Arkansas for Medical Sciences in Little Rock, Arkansas, from January 2013 to June 2017. Women were identified who had twin gestation, were delivered vaginally, and whose maternal age was greater than 18 years old. Women were excluded if they had an intrauterine fetal demise, delivered either/both fetuses via cesarean, history of a previous cesarean or a fetus with a congenital anomaly. If a subject met criteria to be included in the study, the next normal singleton vaginal delivery was used as the control subject.

Results There were 132 singleton vaginal deliveries and 133 twin vaginal deliveries analyzed. There was no significant difference in the length of the third stage of labor between twin and singleton vaginal deliveries except in the 95th percentile of the distribution. Mothers delivering twins had an increase in third-stage duration by 7.618 minutes ( $95 \%$ confidence interval $[\mathrm{Cl}]: 0.73,14.50 ; p=0.03$ ) compared with those who delivered singletons. The twin group had a higher estimated blood loss than singleton deliveries. The increase in blood loss in the twin group was $149.02 \mathrm{~mL}(95 \% \mathrm{Cl}: 100.2,197.8)$,

\section{Keywords}

- postpartum hemorrhage

- twin pregnancy

- third stage of labor

- placental removal $257.01 \mathrm{~mL}$ (95\% Cl: 117.9, 396.1), and $381.53 \mathrm{~mL}$ (95\% Cl: 201.1, 562.1) at the 50th, 90th, and 95th percentiles, respectively. When the third stage of labor was at the 90th percentile or less in twin pregnancy (14 minutes), estimated blood loss was less than $1000 \mathrm{~mL}$. Conclusion Twin pregnancy is a known risk factor for postpartum hemorrhage. As the duration of the third stage prolongs, the risk for hemorrhage also increases. We recommend delivery of the placenta in twin pregnancies by 15 minutes to reduce this risk.
\end{abstract}

\section{Key Points}

- The third stage is longer in twin pregnancy at extremes.

- Twin placentas should be delivered by 15 minutes.

- Manually extract the placenta when third stage is prolonged.

received

April 13, 2020

accepted

May 16, 2020
DOI https://doi.org/

10.1055/s-0040-1715170. ISSN 2157-6998.
Copyright $\odot 2020$ by Thieme Medical

Publishers, Inc., 333 Seventh Avenue, New York, NY 10001, USA. Tel: +1(212) 760-0888.
License terms

$(\circledast) \Theta \circledast$ 
Labor is divided into three stages. The first stage is from onset of labor to complete cervical dilation. The second stage is from complete cervical dilation to delivery of the fetus. The third stage is from delivery of the fetus to delivery of the placenta. A prolonged third stage of labor is generally considered to be a failure of the placenta to deliver within 30 minutes and increases the risk of a postpartum hemorrhage. ${ }^{1}$ Following several studies that reported shorter lengths of the third stage were linked with a postpartum hemorrhage, active management has become the recommend practice. ${ }^{2-4}$ Dombrowski et al reported a median duration of 5 minutes with the 90th percentile of patients delivering the placenta within 13 minutes. $^{3}$ Another study reported a median duration of 4 minutes with a 99th percentile duration of 28 minutes. ${ }^{2}$

There are many obstetric risk factors for a prolonged third stage, including advanced maternal age, nulliparity, extreme obesity, intrapartum fever, and multiple gestation. ${ }^{5,6}$ There is a lack of studies in the literature evaluating the duration of the third stage of labor in twin pregnancies. It is not currently known if the length of the third stage differs from that of singleton deliveries, as a normal length of third stage in twin deliveries has not been established. However, in a retrospective cohort study of 25,160 women, including 171 twin gestations, twin gestation was associated with increased odds of duration of the third stage greater than 30 minutes (odds ratio 10.53). ${ }^{5}$

While prolonged third stage of labor is associated with increased risk of postpartum hemorrhage in singletons, we currently do not know about the contribution of prolonged third stage of labor to postpartum hemorrhage in twin gestations. The aim of this study was to evaluate the length of the third stage of labor and the blood loss at the time of vaginal delivery in twin pregnancies.

\section{Materials and Methods}

This study was conducted as a retrospective cohort to determine the length of the third stage of labor following vaginal delivery of a twin gestation with singleton vaginal deliveries as a control group. The data was collected from deliveries at the University of Arkansas for Medical Sciences in Little Rock, Arkansas, from January 2013 to June 2017. Women were identified who had a vaginal delivery of twins in which both twins were delivered vaginally and whose maternal age was greater than 18 years old. Women were excluded if they had an intrauterine fetal demise, delivered via cesarean, history of a previous cesarean or a fetus with a congenital anomaly. If a subject met criteria to be included in the study, the next normal singleton vaginal delivery was used as the control subject. Blood loss was estimated using marked collection drapes and this estimation was confirmed by pre- and postdelivery hematocrit.

\section{Sample Size Justification}

Our primary outcome of interest was duration of third stage of labor. Based on our previous study with 600 singleton deliveries, the average duration of third stage of labor was 5.8 minutes with a standard deviation of 4 . We hypothesized that women who are pregnant with multiples would have a prolonged third stage of labor by at least $20 \%$ compared with those with singleton deliveries. Therefore, group sample sizes of at least 125 (twin deliveries) and 125 (singleton deliveries) achieve greater than $80 \%$ power to reject the null hypothesis of equal means when the population mean differences is $\mu_{1}-\mu_{2}=5.8-7.3=1.5$ with a standard deviation for both groups of 4 and with a significance level of 0.05 using a two-sided two-sample $t$-test.

\section{Data Analysis}

Maternal characteristics and outcomes including duration of various stages of labor and estimated blood loss were summarized using means and standard deviations for continuous measures and frequency and percentages for categorical data. For non-Gaussian data, we report median along with the 25th and 75th percentiles. Initially to evaluate differences among various maternal factors and outcomes across the two groups (twin pregnancies vs. singleton), two-sample $t$-test or Wilcoxon rank-sum test, as appropriate, was used for continuous variables, while chi-squared test or Fisher's exact test was used for categorical measures. Given that primary goal of the study is examining the relationship between vaginal delivery in twin pregnancies with duration of labor and estimated total blood loss, we used quantile regression $(\mathrm{QR})$ to model the entire conditional distribution of the outcomes. A short coming of multiple regression models is the focus on modeling the conditional mean of the response variable without accounting for the full conditioning distributional properties of the outcome variable. QR allows us to examine not only the conditional median, but more importantly, we can examine the relationships among the outcome and predictor variable at the extreme percentile of interest such as the 90th, 95th, and 99th percentiles. ${ }^{7}$ PROC QUANTREG in SAS 9.4 (SAS Institute Inc., Cary, NC) was used to compute the multivariable $\mathrm{QR}$ models and to conduct statistical inferences on the estimated parameters.

\section{Results}

There were 133 consecutive twin vaginal deliveries meeting inclusion criteria in our cohort and 132 singleton vaginal deliveries were identified and used as the control group. There were no significant differences in age, body mass index (BMI) at time of delivery, diagnosis of chronic hypertension, diabetes, gravidity, and parity between the groups (-Table 1). There were similar rates of induction and spontaneous labor between the groups as well. The distribution of race/ethnicity was statistically different between the twin delivery and singleton groups. More specifically, the proportion of mothers identified as "other" was significantly higher in the singleton group compared with the twin group (25.8 vs. $12.8 \% ; p=0.007$ ). Additionally, there was a significant difference in diagnosis of pre-eclampsia between the twin delivery and control group (18.8 vs. $6.1 \% ; p=0.002$ ).

There was no significant difference in the third stage of labor between twin vaginal deliveries and singleton vaginal deliveries (median duration of 4.5 vs. 4.0 minutes; $p=0.5322$ ). In the twin delivery group, the third-stage duration of the 95th percentile was 23 minutes and 99th percentile was 48 minutes. The 
Table 1 Maternal characteristics and outcomes by group

\begin{tabular}{|c|c|c|c|}
\hline Measure & $\begin{array}{l}\text { Twins group } \\
(n=133)\end{array}$ & $\begin{array}{l}\text { Singleton group } \\
(n=132)\end{array}$ & $p$-Value \\
\hline \multicolumn{4}{|l|}{ Maternal variables } \\
\hline Age, mean $\pm S D$ & $26.8 \pm 5.4$ & $25.7 \pm 5.5$ & 0.094 \\
\hline Race, $n(\%)$ & & & 0.026 \\
\hline White & $62(46.6 \%)$ & $55(41.7 \%)$ & \\
\hline Black & $54(40.6 \%)$ & $43(32.6 \%)$ & \\
\hline Other & $17(12.8 \%)$ & $34(25.8 \%)$ & \\
\hline Delivery BMI $\left(\mathrm{kg} / \mathrm{m}^{2}\right)$, mean \pm SD & $33.0 \pm 6.4$ & $32.2 \pm 8.1$ & 0.412 \\
\hline Chronic HTN, $n(\%)$ & $8(6.1 \%)$ & $10(7.6 \%)$ & 0.625 \\
\hline Diabetes, $n(\%)$ & $6(4.5 \%)$ & $14(10.6 \%)$ & 0.060 \\
\hline Pre-eclampsia, $n(\%)$ & $25(18.8 \%)$ & $8(6.1 \%)$ & 0.002 \\
\hline Gravidity, median (Q1, Q3) & $2(1,4)$ & $2(1,4)$ & $0.229^{a}$ \\
\hline Parity, median $(\mathrm{Q} 1, \mathrm{Q} 3)$ & $1(0,2)$ & $1(0,2)$ & $0.723^{\mathrm{a}}$ \\
\hline Induction, $n(\%)$ & $48(36.1 \%)$ & $56(42.4 \%)$ & 0.291 \\
\hline Spontaneous delivery, $n$ (\%) & $123(93.2 \%)$ & $129(97.7 \%)$ & 0.076 \\
\hline Chorioamnionitis, n (\%) & $5(4.8 \%)$ & $8(6.1 \%)$ & 0.389 \\
\hline Prehematocrit, mean \pm SD & $32.6 \pm 4.0$ & $34.5 \pm 4.2$ & 0.0002 \\
\hline Posthematocrit, mean \pm SD & $28.6 \pm 4.6$ & $30.7 \pm 4.0$ & 0.0001 \\
\hline Hematocrit change, mean \pm SD & $4.1 \pm 3.5$ & $3.8 \pm 2.6$ & 0.446 \\
\hline \multicolumn{4}{|l|}{ Outcome variables } \\
\hline First stage duration (hours), median (Q1, Q3) & $10.29(5.78,17.5)$ & $11.065(6.0,16.925)$ & $0.8093^{\mathrm{a}}$ \\
\hline Second stage duration (mins), median (Q1, Q3) & $38.5(20.0,82.0)$ & $26.0(9.0,58.0)$ & $0.0023^{\mathrm{a}}$ \\
\hline Third stage duration (mins), median (Q1, Q3) & $4.5(3.0,8.0)$ & $4.0(3.0,6.0)$ & $0.5322^{\mathrm{a}}$ \\
\hline Estimated blood loss (mL), median (Q1, Q3) & $500(375,600)$ & $350(250,500)$ & $<0.0001^{\mathrm{a}}$ \\
\hline
\end{tabular}

Abbreviations: BMI, body mass index; HTN, hypertension; SD, standard deviation.

${ }^{\mathrm{a}}$ Analysis based on Wilcoxon rank-sum test; Q1 denotes 25th percentile; Q3 denotes 75th percentile.

Table 2 Summary statistics for the duration of labor and estimated blood loss

\begin{tabular}{|l|l|r|r|r|r|r|r|r|r|}
\hline Group & Variable & Mean & SD & Median & $\begin{array}{l}\text { Lower } \\
\text { quartile }\end{array}$ & $\begin{array}{l}\text { Upper } \\
\text { quartile }\end{array}$ & $\begin{array}{l}\text { 90th } \\
\text { PCT }\end{array}$ & $\begin{array}{l}\text { 95th } \\
\text { PCT }\end{array}$ & $\begin{array}{l}\text { 99th } \\
\text { PCT }\end{array}$ \\
\hline \multirow{5}{*}{ Singleton } & First stage (hours) & 12.63 & 10.12 & 11.065 & 6 & 16.925 & 22.1 & 29 & 36 \\
\cline { 2 - 9 } & Second stage (minutes) & 44.08 & 53.55 & 26 & 9 & 58 & 101 & 145 & 224 \\
\cline { 2 - 9 } & Third stage (minutes) & 5.48 & 3.65 & 4 & 3 & 6 & 11 & 14 & 18 \\
\cline { 2 - 9 } & $\begin{array}{l}\text { Estimated blood loss } \\
\text { (milliliters) }\end{array}$ & 346.71 & 163.36 & 350 & 250 & 500 & 500 & 500 & 800 \\
\hline \multirow{5}{*}{ Twin } & First stage (hours) & 13.63 & 12.80 & 10.29 & 5.78 & 17.5 & 24.67 & 33.8 & 64.6 \\
\cline { 2 - 9 } & Second stage (minutes) & 65.33 & 73.13 & 38.5 & 20 & 82 & 181 & 236 & 325 \\
\cline { 2 - 9 } & Third stage (minutes) & 7.07 & 7.95 & 4.5 & 3 & 8 & 14 & 23 & 48 \\
\cline { 2 - 9 } & $\begin{array}{l}\text { Estimated blood loss } \\
\text { (milliliters) }\end{array}$ & 515.23 & 229.82 & 500 & 375 & 600 & 800 & 1000 & 1200 \\
\hline
\end{tabular}

Abbreviations: PCT, percentile; SD, standard deviation.

control group had a 95th and 99th percentile of 14 and 18 minutes, respectively (see - Table 2 ). In the twin delivery group, the estimated blood loss in the 95th and 99th percentile was 1000 and $1200 \mathrm{~mL}$, respectively, compared with the control group with 500 and $800 \mathrm{~mL}$, respectively. Based on the
Wilcoxon rank-sum test, the amount of estimated blood loss among the twin group was significantly more than the singleton group $(p<0.0001)$.

Analysis of the predelivery and postdelivery hematocrit values of both groups was performed. There was a statistically 
Table 3 Quantile regression estimates for the duration of various stages of delivery and estimated total blood loss

\begin{tabular}{|l|l|l|l|l|}
\hline & Primary predictor: Vaginal delivery group (twins vs. singleton) \\
\hline Outcome & $\begin{array}{l}\text { 50th percentile } \\
\text { estimate (SE) }\end{array}$ & $\begin{array}{l}\text { 90th percentile } \\
\text { estimate (SE) }\end{array}$ & $\begin{array}{l}\text { 95 } \\
\text { estimate } \text { percentile }\end{array}$ & $\begin{array}{l}\text { 99th percentile } \\
\text { estimate (SE) }\end{array}$ \\
\hline First stage of labor (hours) & $-0.412(1.64)$ & $3.358(3.83)$ & $13.204(9.53)$ & $2.792(16.69)$ \\
\hline Second stage of labor (minutes) & $8.654(5.02)$ & $36.920(25.96)$ & $39.992(28.83)$ & $52.740(60.86)$ \\
\hline Third stage of labor (minutes) & $0.094(0.34)$ & $1.347(2.57)$ & $7.618(2.83)^{\mathrm{a}}$ & $18.542(10.59)$ \\
\hline Estimated blood loss (milliliters) & $149.02(25.22)^{\mathrm{a}}$ & $257.01(59.11)^{\mathrm{a}}$ & $381.53(88.26)^{\mathrm{a}}$ & $306.01(285.07)$ \\
\hline
\end{tabular}

Abbreviations: BMI, body mass index; SE, standard error.

Note: We present the regression coefficient for the primary predictor (group). The multivariable quantile regression models are adjusted for maternal age, race, parity, gravidity, BMI at delivery, and pre-eclampsia.

${ }^{\mathrm{a}} \mathrm{p}<0.010$.

significant different in both the predelivery and postdelivery hematocrit values between the singleton and twin groups $(p<0.001)$; however, when comparing the decrease in hematocrit from pre- to postdelivery, there was no difference $(p=0.446)$. The postdelivery hematocrit values were also compared with adjustment for predelivery hematocrit values as a covariate and there was no difference between groups $(p=0.06)$.

Although there was no significant difference in mean duration of the third stage of labor, there was a statistically significant difference in the length of the second stage of labor between twins delivering vaginally and singletons delivering vaginally. The median length of the second stage of labor was longer in the twin group compared with the control group (38.5 vs. 26.0 minutes).

The results of the QR models are presented in - Table 3. Here, we examined the relationships between vaginal delivery groups (twins vs. singleton) with outcomes at the various percentiles including the median, 90th, 95th, and 99th while adjusting for key maternal factors including maternal age, race, parity, gravidity, delivery BMI, and pre-eclampsia. Regardless of the percentiles, there were no statistical differences in the durations for first or second stage of labor between the groups after adjusting for the various maternal factors. Third-stage duration increased by 7.618 minutes among those mothers delivering twins (95\% confidence interval $[\mathrm{Cl}]: 0.73,14.50$; $p=0.03$ ). Finally, the twin vaginal delivery group was highly associated with increased estimated blood loss between the 50th and 95th percentiles. Among those mothers delivering twins, blood loss increased by $149.02 \mathrm{~mL}$ (95\% CI: 100.2 , 197.8), $257.01 \mathrm{~mL}$ (95\% CI: $117.9,396.1$ ), and $381.53 \mathrm{~mL}$ (95\% CI: 201.1, 562.1) in the 50th, 90th, and 95th percentiles, respectively.

\section{Discussion}

\section{Principal Findings}

We found the mean duration of the third stage of labor is not increased in twin vaginal deliveries compared with singleton pregnancies.

Previous studies examining the duration of the third stage in singleton vaginal deliveries concur with the findings of the duration in our control group. ${ }^{2,3,8}$ We did not find a difference in mean duration of the third stage of labor; however, when examining the 95th and 99th percentiles of duration there was a significant difference between the groups.

\section{Clinical Implications}

An abnormal duration of the third stage in pregnancies is not known, as most textbooks and guidelines use 30 minutes as a prolonged third stage for singletons. The 95th percentile is often used in statistical analysis as the upper limit of normal. A study by Frolova et al reported the 95th percentile for duration of the third stage to be 13 minutes. ${ }^{2}$ The risk of maternal morbidity appears to be with a duration greater than 18 to 20 minutes. ${ }^{2,8-10}$ In a prospective observational study of over 600 women, a third stage of labor greater than 15 minutes increased the risk of blood loss over $500 \mathrm{~mL}$ by 15.8 times. ${ }^{11}$ Although in our study the mean and median did not differ between the twin group and control group, the 95th and 99th percentiles were increased in the twin group compared with the control group as well as the estimated blood loss, with 95th and 99th percentiles of the twin group increased by 381 and $306 \mathrm{cc}$, respectively. When examining predelivery and postdelivery hematocrits, there was no statistically significant difference between the singleton and twin group. Calculated blood loss using hematocrit values was not performed as hematologic values may be altered by multiple factors including hydration in the intrapartum and postpartum period, pregnancy-induced hypertension, and normal maternal physiologic blood volume changes. ${ }^{12}$ Therefore, a lack in a significant change in hematocrit may not be an accurate assessment of blood loss as we identified no studies examining the accuracy of calculated blood loss in twin pregnancies. Interestingly, blood loss from singleton delivery at the 99th percentile for third-stage duration (18 minutes, $800 \mathrm{~mL}$ ) is comparable to blood loss from twin delivery at only the 90th percentile for third-stage duration (14 minutes, $800 \mathrm{~mL}$ ). These findings may infer that more aggressive management of the third stage of labor in twin pregnancies may be appropriate. The most common intervention for a prolonged third stage among practitioners is manual extraction of the placenta. 3,10

There are likely multiple factors contributing to the increased blood loss as twin pregnancies experience over 
distention of the uterus and are more likely to have other complications of pregnancy including diabetes and hypertensive disorders. ${ }^{13}$ However, minimizing the duration of the third stage with active management could reduce the risk of excessive blood loss.

\section{Strengths and Weaknesses}

A strength of this study is this is the first study published specifically evaluating the third stage of labor duration in twin vaginal deliveries. Limitations of this study included the retrospective nature of the study. Even though there were 133 and 132 patients in each arm, we may still have been underpowered to detect rare outcomes.

\section{Conclusion}

Prolonged third stage of labor may have a different definition in twin compared with singleton vaginal delivery. Since twin gestation is an independent risk factor for hemorrhage, we may need to manage the third stage more aggressively to reduce this risk of hemorrhage. Based upon this study, and based on prior data, we would recommend delivery of the placenta by 15 minutes, which is around the 90th percentile for twin gestation third stage length.

\section{Financial Disclosure}

No funding or financial support was received for this work.

\section{Disclaimer}

The opinions or assertions contained herein are the private views of the authors and are not to be construed as the official policy of the Department of the Army, Department of Defense, or the US government.

\section{Conflict of Interest}

None.

\section{References}

1 Combs CA, Murphy EL, Laros RK Jr. Factors associated with postpartum hemorrhage with vaginal birth. Obstet Gynecol 1991;77(01):69-76

2 Frolova AI, Stout MJ, Tuuli MG, López JD, Macones GA, Cahill AG. Duration of the third stage of labor and risk of postpartum hemorrhage. Obstet Gynecol 2016;127(05):951-956

3 Dombrowski MP, Bottoms SF, Saleh AA, Hurd WW, Romero R. Third stage of labor: analysis of duration and clinical practice. Am J Obstet Gynecol 1995;172(4 Pt 1):1279-1284

4 Magann EF, Lutgendorf MA, Keiser SD, et al. Risk factors for a prolonged third stage of labor and postpartum hemorrhage. South Med J 2013;106(02):131-135

5 Shinar S, Shenhav M, Maslovitz S, Many A. Distribution of thirdstage length and risk factors for its prolongation. Am J Perinatol 2016;33(10):1023-1028

6 Cummings KF, Helmich MS, Ounpraseuth ST, Dajani NK, Magann EF. The third stage of labour in the extremely obese parturient. J Obstet Gynaecol Can 2018;40(09):1148-1153

7 Cade B, Noon B. A gentle introduction to quantile regression for ecologists. Front Ecol Environ 2003;1:412-420

8 Magann EF, Evans S, Chauhan SP, Lanneau G, Fisk AD, Morrison JC. The length of the third stage of labor and the risk of postpartum hemorrhage. Obstet Gynecol 2005;105(02):290-293

9 Magann EF, Doherty DA, Briery CM, Niederhauser A, Chauhan SP, Morrison JC. Obstetric characteristics for a prolonged third stage of labor and risk for postpartum hemorrhage. Gynecol Obstet Invest 2008;65(03):201-205

10 Cummings K, Doherty DA, Magann EF, Wendel PJ, Morrison JC. Timing of manual placenta removal to prevent postpartum hemorrhage: is it time to act? J Matern Fetal Neonatal Med 2016;29(24):3930-3933

11 Rabie NZ, Ounpraseuth S, Hughes D, Lang P, Wiegel M, Magann EF. Association of the length of the third stage of labor and blood loss following vaginal delivery. South Med J 2018;111(03):178-182

12 Stafford I, Dildy GA, Clark SL, Belfort MA. Visually estimated and calculated blood loss in vaginal and cesarean delivery. Am J Obstet Gynecol 2008;199(05):519.e1-519.e7

13 Santana DS, Cecatti JG, Surita FG, et al; WHO Multicountry Survey on Maternal and Newborn Health Research Network. Twin pregnancy and severe maternal outcomes: the World Health Organization multicountry survey on maternal and newborn health. Obstet Gynecol 2016;127(04):631-641 